\title{
Singlet Oxygen Generation from Water-Soluble Quantum Dot- Organic Dye Nanocomposites
}

\author{
Lixin Shi, Billy Hernandez, and Matthias Selke \\ Department of Chemistry and Biochemistry, California State University, Los Angeles, Los \\ Angeles, CA90032-8202
}



Water-soluble quantum dot - organic dye nanocomposites have been prepared via electrostatic interaction. We used CdTe quantum dots with diameters up to $3.4 \mathrm{~nm}, 2$-aminoethanthiol as a stabilizer, and meso-tetra (4-sulfonatophenyl) porphine dihydrochloride (TSPP) as an organic dye. The photophysical properties of the nanocomposite have been investigated. The fluorescence of the parent CdTe quantum dot is largely suppressed. Instead, indirect excitation of the TSPP moiety leads to production of singlet oxygen with a quantum yield of 0.43 . The nanocomposite is sufficiently photostable for biological applications.

Colloidal semiconductor nanocrystals (Quantum Dots, QDs) can provide three-dimensional (3D) architectures and have attracted widespread interest, since their nano-size physical properties are quite different from those of bulk materials. ${ }^{1}$ QDs photoluminescence can be size-tuned to improve spectral overlap with a particular acceptor, and having several acceptors interact with a single QDs donor substantially improves fluorescence resonance energy transfer (FRET) efficiency. Retaining the small probe size is critical for successful in vivo applications since large-sized probes significantly reduce biostability, diffusion, and circulation processes, and increase undesired nonspecific binding. ${ }^{2}$ The small size of QDs is valuable for enhancing biological targeting efficiency and specificity. ${ }^{3}$

Photodynamic therapy (PDT) is an emerging modality for the treatment of a variety of oncological, dermatological, and other types of cancer. ${ }^{4}$ Singlet oxygen $\left({ }^{1} \mathrm{O}_{2}\right)$ is believed to be a major cyctotoxic species in this process. There have been several reports of nanoparticles as carriers for singlet oxygen photosensitizers. ${ }^{5-7}$ Nanoparticles can be ideal carriers of photosensitizer molecules for PDT. Moreover, some nanomaterials can generate singlet oxygen. ${ }^{8,9}$ Although this area has not received as much attention as the application of nanomaterials to electronics or catalysis, it represents a promising route to overcoming many

Correspondence to: Matthias Selke.

mselke@calstatela.edu .

Supporting Information Available: Detailed procedures regarding sample preparation and assay conditions for CdTe and CdTeTSPP nanocomposites. This material is available free of charge via the Internet at http://pubs.acs.org 
of the difficulties associated with traditional PDT. ${ }^{10}$ Studies of electron transfer between QDs and organic dyes have recently attracted attention as well. ${ }^{11}$ Burda et al. have reported that a CdSe QD-sensitizer hybrid is able produce singlet oxygen via a FRET mechanism. ${ }^{7}$ However, this species was not soluble in water, thus limiting biological applications. Furthermore, no quantum yields for singlet oxygen production for any QD-organic dye nanocomposites have been published to date. Water-soluble species with a high ${ }^{1} \mathrm{O}_{2}$ quantum yield are critical for artificial biocompatibility materials used as drug delivery carriers, and in vivo imaging. A cyclometalated Ir-complex type sensitizier ${ }^{12}$ attached to a $^{-}$ $\mathrm{CdSe} / \mathrm{ZnS} \mathrm{QD}$ has also just been reported; however, in this system, the Ir complex was directly excited. ${ }^{13}$

We report herein the preparation of water-soluble QDs, using Meso-Tetra (4sulfonatophenyl) Porphine Dihydrochloride (TSPP) as a photosensitizer, bound to CdTe nanocrystals via electrostatic interactions. The advantage of the electrostatic approach used in our work is that it allows control over the assembly behavior in solution. ${ }^{14}$

The CdTe QDs were synthesized with 2-aminoethanethiol as surface stabilizer. Synthesis of yellow photofluorescence CdTe nanocrystal was performed via a modified protocol adopted from the literature. ${ }^{15}$ The CdTe QDs revealed size-dependent luminescence with maxima at $560 \mathrm{~nm}$. In a typical assay, the UV-vis spectra of QD-TSPP nanocomposites shifted slightly to the blue region,compared with free TSPP (Figure 1a). This could be surface caused by surface plasma changes as TSPP deposited on the of the QDs aggregates. ${ }^{16}$ The UV-vis peak of CdTe-TSPP nanocomposites increased with the concentration of added

TSPP.Immediate aggregation was observed when the concentration of TSPP reached $6 \times 10^{-2}$ $\mathrm{mM}$. There is no obvious increase in the absorption peak of the QDs after combination with TSPP. The extinction coefficient of TSPP at $355 \mathrm{~nm}$ is very small. After TSPP was deposited on the QDs surface, the extinction coefficient of the nanocomposite at $355 \mathrm{~nm}$ increased significantly (almost tenfold) to $18300 \mathrm{M}^{-1}$. The emission intensity of CdTe-TSPP nanocomposites decreased strongly when TSPP was deposited on the CdTe surface, suggesting energy transfer to the TSPP moiety (Fig.1). Interestingly, an absorption shift to $670 \mathrm{~nm}$ occurs concurrently with this energy transfer.

High resolution transmission electron microscopy (HRTEM) was used to characterize the structures of the processed particles and composites as shown in Figure 2. The main diameter of the CdTe core determined by TEM was $3.4 \mathrm{~nm}$ (with a standard deviation of 1.2 $\mathrm{nm}$ ). Varying electron diffractive patterns were observed. A representative TEM image of the processed CdTe-TSPP composites showed sizes ranging from 6 to $8 \mathrm{~nm}$. Magnification of these composites did not reveal the presence of aggregated clusters. However, no obvious electron diffractive patterns were present. We attribute these observations to enhanced packing passivation of the composites achieved due to the organic dye deposited on the nanocrystal surface.

Upon excitation by near UV or visible light, the QD-TSPP composite does indeed produce singlet oxygen. To elucidate the mechanism of singlet oxygen production, we carried out detailed photophysical studies at $355 \mathrm{~nm}$. Absorption of free TSPP is only about $10 \%$ of that of the nanocomposite at this wavelength. Therefore, if an appreciable amount of singlet oxygen is detected at this wavelength, it must have been produced via excitation of the quantum dot. Excitation of the nanocomposite with a Nd:YAG laser at $355 \mathrm{~nm}$ does indeed produce the characteristic ${ }^{1} \mathrm{O}_{2}$ emission signal in the near-infrared region. Addition of sodium azide to the solution leads to a sharp decline of the lifetime of this emission, demonstrating that the signal was indeed due to singlet oxygen. Singlet oxygen quantum yield (QY) measurements were carried out in $\mathrm{D}_{2} \mathrm{O}$ at $355 \mathrm{~nm}$, using free TSPP as a reference. The singlet oxygen luminescence intensity was plotted vs. the optical density of 
the solution at the excitation wavelength. The ratio of the slopes thus obtained gives the ratio of the quantum yields of the nanocomposite vs. that of the reference compound (Fig. 3). The ratio of the QY of ${ }^{1} \mathrm{O}_{2}$ of the CdTe-TSPP nanocomposites vs. free TSPP is 0.67 in $\mathrm{D}_{2} \mathrm{O}$. Using the literature value of 0.64 for the singlet oxygen QY of TSPP, ${ }^{17}$ we obtain a quantum yield for the production of singlet oxygen by the nanocomposite of 0.43 at $355 \mathrm{~nm}$. No singlet oxygen was observed when the CdTe nanocrystal was excited in the absence of TSPP. This is similar to Donegá's report, ${ }^{18}$ but in contrast with the work of Burda et al. who observed a small amount ( 5\%) of singlet oxygen formed directly from a CdSe QD. ${ }^{7}$ Since we obtained a QY of 0.43 for our nanocomposite at a wavelength where absorption of the free sensitizer is minimal, we suggest that singlet oxygen is produced via excitation of the QD followed by a FRET-type mechanism. Support for this hypothesis is obtained by the observation that the emission of the CdTe QD is greatly diminished after the TSPP is added to form the nanocomposite (Fig. 1b).

Photooxidation experiments were also carried out in the visible range (cut-off at $492 \mathrm{~nm}$ ) to determine the stability of the nanocomposites and possible oxidation of the nanocomposites by ${ }^{1} \mathrm{O}_{2}$. Methionine was oxidized to the corresponding sulfone, consistent with singlet oxygen production. The stability of the nanocomposite was also monitored during these reactions. At high concentrations $\left(3.0 \times 10^{-2} \mathrm{mM}\right)$ of the nanocomposite, no decomposition was detected by ${ }^{1} \mathrm{H}$ NMR spectroscopy over a period of $1 \mathrm{~h}$. At lower concentrations, irradiation of the samples for $30 \mathrm{~min}$ did not lead to any changes, which is a time-frame sufficient for biological applications, such as PDT. ${ }^{19}$ Prolonged irradiation at low concentration resulted in a decrease in the absorption spectra of the CdTe-TSPP nanocomposite.

We have thus established that water-soluble quantum dot-organic dye nanocomposites can produce singlet oxygen with a quantum yield that is sufficiently high for biological applications. Such nanocomposites may therefore be used as model systems for living organism imaging and photodynamic therapy. Increasing the size of the QD should shift its absorption to the red region, and changing the length of the aminothiol stabilizer may affect the efficiency of FRET to the TSPP. Experiments to elucidate the magnitude of these effects are currently in progress.

\section{Supplementary Material}

Refer to Web version on PubMed Central for supplementary material.

\section{Acknowledgments}

The authors thank for Ms. Carol Garland (California Institute of Technology) for help with the TEM experiment. We gratefully acknowledge support from the NSF-PREM program (Award No. 0351848) and from the NIHNIGMS MBRS program (Award No. GM08101).

\section{References}

1. a Alivisatos AP. Science. 1996; 271:933.b Michalet X, Pinaud FF, Bentolila LA, Tsay JM, Doose S, Li JJ, Sundaresan G, Wu AM, Gambhir SS, Weiss S. Science. 2005; 307:538. [PubMed: 15681376] c Burda C, Chen XB, Narayanan R, El-Sayed MA. Chem. Rev. 2005; 105:1025. [PubMed: 15826010]

2. a Chan WCW, Maxwell DJ, Gao XH, Bailey RE, Niu SM. Curr. Opin. Biotechnol. 2002; 13:40. [PubMed: 11849956] b Gao XH, Yang L, Petros JA, Marshall FF, Simons JW, Niu SM. Curr. Opin. Biotechnol. 2005; 16:63. [PubMed: 15722017] c Pouliquen D, Le Jeune JJ, Perdrisot R, Ermias A, jallet P. Magn. Reson. Imaging. 1991; 9:275. [PubMed: 1881245] 
3. a Medintz IL, Clapp AR, Mattoussi H, Goldman ER, Fisher B, Mauro JM. Nat. Mater. 2003; 2:630. [PubMed: 12942071] b Bakalova R, Ohba H, Zhelev Z, Nagase T, Jose R, Ishikawa M, Baba Y. Nano Lett. 2001; 4:1567.

4. a Yokoyama M, Satoh A, Sakurai A, Okano T, Matsumura Y, Kakizoe T, Kataoka K. J. Control. Release. 1998; 55:219. [PubMed: 9795065] b Leroux J-C, Allémann E, Jaeghere FD, Doelker E, Gurny R. J. of Control. Release. 1996; 39:339.

5. a Imahori H, Arimura M, Hanada T, Nishimura Y, Yamazaki I, Sakata Y, Fukuzumi S. J. Am. Chem. Soc. 2001; 123:335. [PubMed: 11456522] b Roy I, Ohulchanskyy TY, Pudavar HE, Bergey EJ, Oseroff AR, Morgan J, Dougherty TJ, Prasad PN. J. Am. Chem. Soc. 2003; 125:7860. [PubMed: 12823004]

6. Hone DC, Walker PI, Evans-Growing R, FitzGerald S, Beeby A, Chambrier I, Cook MJ, Russell DA. Langmuir. 2002; 18:2985.

7. Samia ACS, Chen XB, Burda C. J. Am. Chem. Soc. 2003; 125:15736. [PubMed: 14677951]

8. Wang SZ, Gao RM, Zhou FM, Selke M. J. Mater. Chem. 2004; 14:487.

9. Argobast JW, Darmanyan AP, Foote CS, Diederich FN, Rubin Y, Diederich F, Alvarez M, Anz SJ, Whetten RL. J. Phys. Chem. 1991; 95:11.

10. Bakalova R, Ohba H, Zhelev Z, Nagase T, Jose R, Ishikawa M, Ba Y. Nano Lett. 2004; 4:1567.

11. a Clapp AR, Medintz IL, Fisher BR, Anderson GP, Mattoussi H. J. Am. Chem. Soc. 2005; 127:1242. [PubMed: 15669863] b Clapp AR, Medintz IL, Mauro JM, Fisher BR, Bawendi MG, Mattoussi H. J. Am. Chem. Soc. 2004; 126:301. [PubMed: 14709096] b Mattoussi H, Mauro JM, Goldman ER, Anderson GP, Sundar VC, Mikulec FV, Bawendi MG. J.Am. Chem. Soc. 2000; 122:12142.

12. Gao RM, Ho DG, Hernandez B, Selke M, Murphy D, Djurovich P, Thompson ME. J. Am. Chem. Soc. 2002; 124:14828. [PubMed: 12475307]

13. Hsieh JM, Ho ML, Wu PW, Chou PT, Tsai TT, Chi Y. Chem. Comm. 2006:615. [PubMed: 16446827]

14. Gelid DM, Zilbermann I, Anderson G, Kotov NA, Tagmatarchis N, Prato M. J. Am. Chem. Soc. 2004; 126:14340. [PubMed: 15521738]

15. a Gao MY, Kirstein S, Möhwald H, Rogach AL, Kornowski RA, Eychmüller A, Weller H. J. Phys. Chem. B. 1998; 102:8360.b Zhang H, Zhou Z, Yang B, Gao MY. J. Phys. Chem. B. 2003; 107:8.c Zhang H, Cui ZC, Wang Y, Zhang K, Ji X, Lu CL, Yang B, Gao MY. Adv. Mater. 2003; 15:777.

16. Luo YH, Huang JG, Ichinose I. J. Am. Chem. Soc. 2005; 127:8296. [PubMed: 15941258]

17. Davila J, Harriman A. Photochem. Photobio. 1990; 51:9.

18. Wuister SF, Swart I, Driel FV, Hickey SG, Donegá CDM. Nano Lett. 2003; 3:503.

19. Konan YN, Guny R, Allemann E. J. Photochem. Photobio. B. 2002; 66:89. 

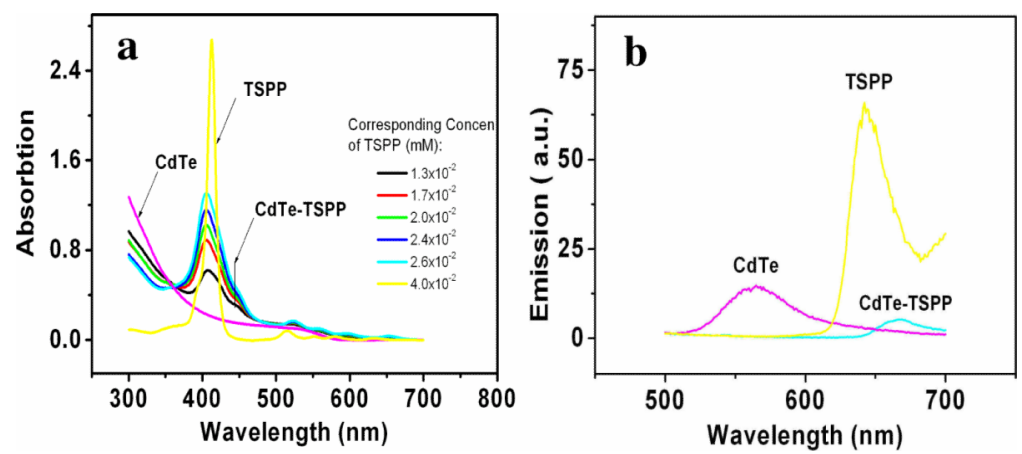

Figure 1a.

UV-vis spectra for the fabrication of CdTe with TSPP in $0.1 \mathrm{M} \mathrm{pH} 7.0$ phosphate buffer solution. Spectrum 1 (yellow) corresponds to the free TSPP $\left(4 \times 10^{-2} \mathrm{mM}\right)$, while spectrum 2 (pink) corresponds to CdTe nanocrystals. The other spectra show formation of the CdTeTSPP composite. $1 \boldsymbol{b}$. Emission spectra of CdTe, TSPP and CdTe-TSPP nanocomposites, respectively. Excitation wavelength: $400 \mathrm{~nm}$. 

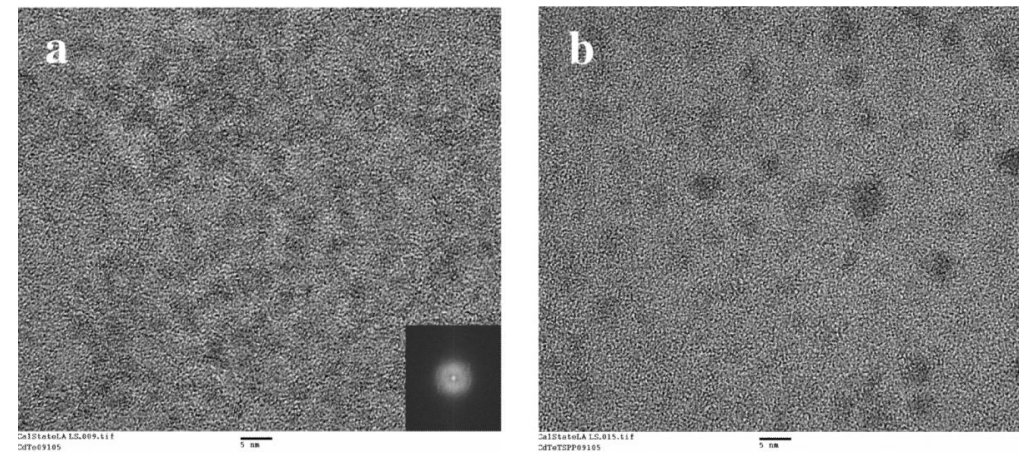

Figure 2.

High resolution TEM image of CdTe nanocrystals $\left(10^{-3} \mathrm{mM}\right)$, a), and CdTe-TSPP nanocomposites ( $10^{-3} \mathrm{mM}$ CdTe with $10^{-2} \mathrm{mM}$ TSPP), b). Scale bar is $5 \mathrm{~nm}$. 


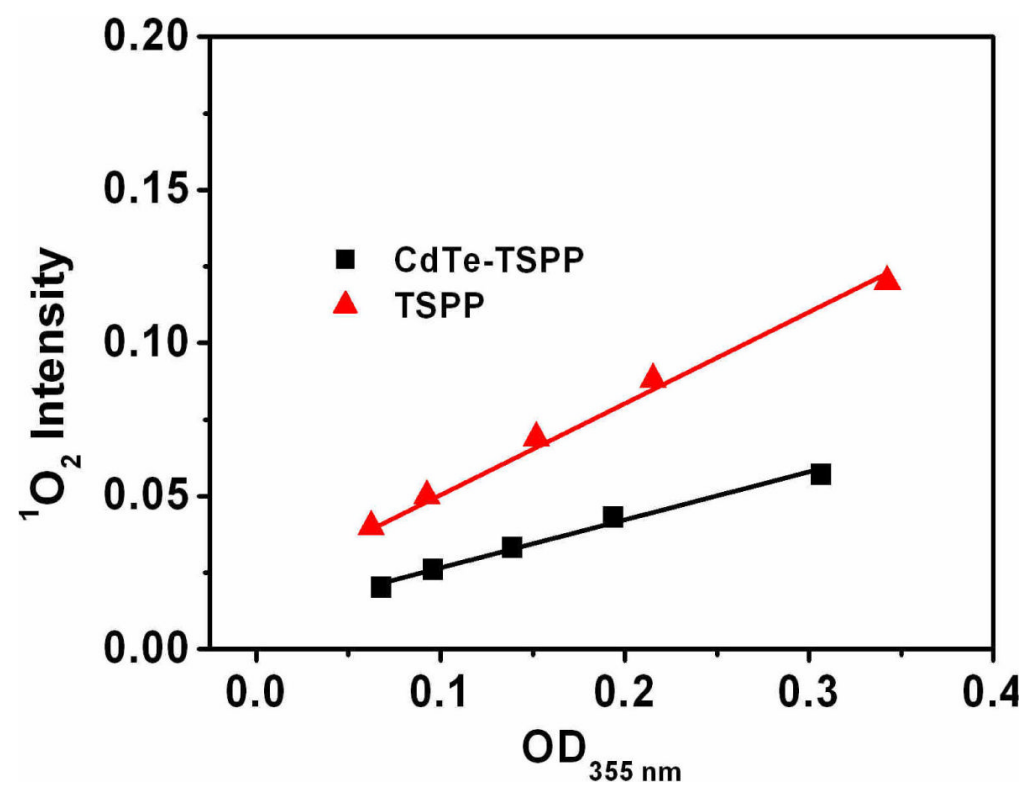

Figure 3.

Relative intensity of singlet oxygen production $v s$ optical density of CdTe-TSPP nanocomposites or TSPP, excitation at $355 \mathrm{~nm}$. 